\title{
Global Terrestrial Ecosystem Carbon Flux Inferred from TanSat $\mathrm{XCO}_{2}$ Retrievals
}

\author{
Hengmao Wang, ${ }^{1}$ Fei Jiang $\left(\mathbb{D},{ }^{1,2}\right.$ Yi Liu, ${ }^{3}$ Dongxu Yang, ${ }^{3}$ Mousong Wu, ${ }^{1}$ Wei He $\left(\mathbb{D},{ }^{1}\right.$ \\ Jun Wang $\mathbb{D}^{1},{ }^{1}$ Jing Wang, ${ }^{3}$ Weimin Ju, ${ }^{1}$ and Jing M. Chen $\mathbb{D}^{1,4}$ \\ ${ }^{1}$ Jiangsu Provincial Key Laboratory of Geographic Information Science and Technology, International Institute for Earth \\ System Science, Nanjing University, Nanjing 210023, China \\ ${ }^{2}$ Jiangsu Center for Collaborative Innovation in Geographical Information Resource Development and Application, \\ Nanjing 210023, China \\ ${ }^{3}$ Institute of Atmospheric Physics, Chinese Academy of Sciences, Beijing 100029, China \\ ${ }^{4}$ Department of Geography, University of Toronto, Toronto, Ontario, Canada M5S3G3 \\ Correspondence should be addressed to Fei Jiang; jiangf@nju.edu.cn
}

Received 12 July 2021; Accepted 7 December 2021; Published 11 January 2022

Copyright (c) 2022 Hengmao Wang et al. Exclusive Licensee Aerospace Information Research Institute, Chinese Academy of Sciences. Distributed under a Creative Commons Attribution License (CC BY 4.0).

\begin{abstract}
TanSat is China's first greenhouse gases observing satellite. In recent years, substantial progresses have been achieved on retrieving column-averaged $\mathrm{CO}_{2}$ dry air mole fraction $\left(\mathrm{XCO}_{2}\right)$. However, relatively few attempts have been made to estimate terrestrial net ecosystem exchange (NEE) using TanSat $\mathrm{XCO}_{2}$ retrievals. In this study, based on the GEOS-Chem 4D-Var data assimilation system, we infer the global NEE from April 2017 to March 2018 using TanSat $\mathrm{XCO}_{2}$. The inversion estimates global NEE at $-3.46 \mathrm{PgC} \mathrm{yr}^{-1}$, evidently higher than prior estimate and giving rise to an improved estimate of global atmospheric $\mathrm{CO}_{2}$ growth rate. Regionally, our inversion greatly increases the carbon uptakes in northern mid-to-high latitudes and significantly enhances the carbon releases in tropical and southern lands, especially in Africa and India peninsula. The increase of posterior sinks in northern lands is mainly attributed to the decreased carbon release during the nongrowing season, and the decrease of carbon uptakes in tropical and southern lands basically occurs throughout the year. Evaluations against independent $\mathrm{CO}_{2}$ observations and comparison with previous estimates indicate that although the land sinks in the northern middle latitudes and southern temperate regions are improved to a certain extent, they are obviously overestimated in northern high latitudes and underestimated in tropical lands (mainly northern Africa), respectively. These results suggest that TanSat $\mathrm{XCO}_{2}$ retrievals may have systematic negative biases in northern high latitudes and large positive biases over northern Africa, and further efforts are required to remove bias in these regions for better estimates of global and regional NEE.
\end{abstract}

\section{Introduction}

Satellite-based measurements of column-averaged $\mathrm{CO}_{2}$ dry air mole fraction $\left(\mathrm{XCO}_{2}\right)$ provide global coverage at high spatial resolution and support top-down estimates of surface $\mathrm{CO}_{2}$ sinks and sources at global and regional scales, which is critical to future projections of climate change and effective carbon reduction strategy. In the past decade, a serial of satellite missions dedicated to measure $\mathrm{XCO}_{2}$ have been launched and international measurement records have been greatly expanded. The Japanese Greenhouse Gases Observing Satellite (GOSAT) has been collecting data since 2009 [1]. The Orbiting Carbon Observatory 2 (OCO-2) launched by the US National Aeronautics and Space Administration (NASA) has been in operation since August of $2014[2,3]$. The China's greenhouse gas monitoring satellite mission (TanSat) [4] was launched in December of 2016 and followed by GOSAT-2 [5] in October of 2018 and OCO-3 [6] in May of 2019. These carbon satellites fly at low orbit and measure near-infrared sunlight reflected from the 
surface in $\mathrm{CO}_{2}$ spectral bands and the $\mathrm{O}_{2} \mathrm{~A}$ band to retrieve $\mathrm{XCO}_{2}$, with the primary scientific objective of monitoring of surface carbon sinks and sources.

Substantial progresses have been achieved in using $\mathrm{XCO}_{2}$ data from GOSAT and OCO-2 to estimate terrestrial ecosystem carbon exchange (NEE) [7-15]. Attempts were also made to quantify anthropogenic $\mathrm{CO}_{2}$ sources using $\mathrm{XCO}_{2}$ retrievals [16-18]. These studies confirmed the advantages of satellitebased measurement of $\mathrm{XCO}_{2}$ in estimating the major carbon sinks and sources and shown that the use of $\mathrm{XCO}_{2}$ retrievals could improve our understanding of the carbon cycle.

TanSat, supported by the Ministry of Science and Technology of China, the Chinese Academy of Sciences, and the China Meteorological Administration, was launched on 22 Dec 2016 and started collecting measurements operationally in March 2017 [19, 20]. It flies in a sun-synchronous low Earth orbit (LEO) that crosses the equator around 13:30 local time. There are two instruments on-board: the Atmospheric Carbon Dioxide Grating Spectrometer (ACGS) and the Cloud and Aerosol Polarimetry Imager (CAPI). The ACGS is a hyperspectral grating spectrometer that measures backscattered sunlight in three NIR/SWIR bands. The CAPI is a multiband imager that measures in five bands from UV to NIR. TanSat operates in three viewing modes: nadir, glint, and target. The swath width of TanSat measurements is $\sim 18 \mathrm{~km}$ across the satellite track and contains 9 footprints each with a size of $2 \mathrm{~km} \times 2 \mathrm{~km}$ at nadir [11,21].

Since launch, several research teams in China have made tremendous efforts to retrieve $\mathrm{XCO}_{2}$ from TanSat measurements. Overcoming the challenges of eliminating the systematic calibration biases, and addressing the instrument degradation and the weak signal-to-noise ratio for certain spectral bands as well, they have successfully produced $\mathrm{XCO}_{2}$ products. Yang et al. [4] developed the Institute of Atmospheric Physics Carbon dioxide retrieval Algorithm for Satellite measurement (IAPCAS) and produced the first global $\mathrm{XCO}_{2}$ product from TanSat observations. To further improve the retrieval accuracy, Yang et al. [22] developed a spectrum correction method and applied the University of Leicester Full Physics (UoL-FP) algorithm for TanSat nadir mode $\mathrm{XCO}_{2}$ retrievals. Evaluated against TCCON retrievals, the TanSat $\mathrm{XCO}_{2}$ retrievals have a mean bias and RMSE of $-0.08 \mathrm{ppm}$ and $1.47 \mathrm{ppm}$, respectively. Applying this correction method, a new TanSat $\mathrm{XCO}_{2}$ product that retrieved by IAPCAS algorithm shows an improvement on accuracy and precision [23]. Wang et al. [24] implemented NASA Atmospheric $\mathrm{CO}_{2}$ Observations from Space (ACOS) algorithm with TanSat measurements to retrieve $\mathrm{XCO}_{2}$. Hong et al. [25] retrieved $\mathrm{XCO}_{2}$ at TanSat glint mode with spectral recalibration and using the Iterative Maximum A Posteriori Differential Optical Absorption Spectroscopy (IMAP-DOAS) algorithm.

The major scientific goal of the TanSat mission is to quantify carbon sinks and sources at global and regional scales. However, relatively few attempts have been made to utilize TanSat $\mathrm{XCO}_{2}$ retrieval to estimate surface carbon fluxes. Yang et al. [26] took the initial step to derive surface carbon flux from TanSat $\mathrm{XCO}_{2}$ retrievals, focusing on net carbon budget over land and without evaluating inversion results using independent $\mathrm{CO}_{2}$ observations. In this study, we conduct the inversion using the GEOS-Chem Adjoint 4D-Var assimilation system, which has been successfully applied with GOSAT and OCO-2 $\mathrm{XCO}_{2}$ retrievals [27]. Different from Yang et al. [26], we focus on the optimization of NEE, which has the largest uncertainty among all carbon components in the carbon cycle and has aroused great interest in the carbon cycle research community. And most previous inversion studies focused on NEE. Therefore, by comparing with previous studies, we can analyze and discuss the rationality of our inversion results. We explore the potential of TanSat $\mathrm{XCO}_{2}$ retrievals in improving the estimates of NEE in different regions and evaluate the inversion results using surface flask $\mathrm{CO}_{2}$ observations and Total Carbon Column Observing Network (TCCON) $\mathrm{XCO}_{2}$ retrievals. The paper is organized as follows: Section 2 briefly introduces TanSAT $\mathrm{XCO}_{2}$ retrievals, and the inversion methodology and settings. Section 3 presents results and discussions. Conclusions are given in Section 4.

\section{Data and Method}

2.1. The GEOS-Chem Inverse Modeling Framework. The GEOS-Chem model [28] is a global three-dimensional chemistry transport model (CTM), which enables atmospheric composition simulations on local to global scales. It is developed and used by hundreds of research groups worldwide (http://geos-chem.org). The original $\mathrm{CO}_{2}$ simulation in the GEOS-Chem model was developed by Suntharalingam et al. [29] and updated by Nassar et al. [30]. In this study, the GEOS-Chem model was run from March 1, 2017, to April 1, 2018 in a horizontal resolution of $4^{\circ} \times 5^{\circ}$ for 47 vertical layers. The posterior $\mathrm{CO}_{2}$ field on Mar 1, 2017, from NOAA's CarbonTracker version CT2019 [31] was taken as the initial concentration. The first month was treated as spin-up, and the results from April 2017 to March 2018 were analyzed in this study.

The inverse modeling of $\mathrm{CO}_{2}$ flux was implemented using the $4 \mathrm{D}$-Var data assimilation approach based on the GEOSChem Adjoint model [32]. The prior carbon fluxes used in this study consist of fossil fuel emission, biomass burning emission, terrestrial $\mathrm{NEE}$, and $\mathrm{CO}_{2}$ exchanges over the ocean surface. Fossil fuel emission is from CT2019, which is an average of Carbon Dioxide Information Analysis Center (CDIAC) product [33] and Open-source Data Inventory of Anthropogenic $\mathrm{CO}_{2}$ (ODIAC) emission product [34]. NEE is from the simulations of the Simple Biosphere Model Carnegie-Ames-Stanford Approach (SiBCASA) biogeochemical model [35]. Biomass burning $\mathrm{CO}_{2}$ emission is also from the simulations of SiBCASA model based on the Global Fire Emissions Database version 4 (GFEDv4) [36]. $\mathrm{CO}_{2}$ exchanges over the ocean surface are from the Jena CarboScope sea-air $\mathrm{CO}_{2}$ flux dataset estimated from the Surface Ocean $\mathrm{CO}_{2}$ Atlas (SOCAT) data set of $\mathrm{pCO}_{2}$ observations [37]. Due to their relatively small uncertainties at global and continental scales, the fossil fuel emission and the biomass burning emission in our inversion are prescribed. The NEE and ocean $\mathrm{CO}_{2}$ fluxes are optimized on monthly scale and a global $4^{\circ} \times 5^{\circ}$ grid. The scaling factors of the NEE and ocean $\mathrm{CO}_{2}$ fluxes are optimized 
monthly in each model grid by minimizing the cost function, $J$ , given by the following:

$$
\begin{aligned}
J(\mathrm{c})= & \frac{1}{2} \sum_{i=1}^{N}\left(\mathrm{XCO}_{2, i}^{m}-\mathrm{XCO}_{2, i}^{\mathrm{obs}}\right) R_{\mathrm{obs}, i}^{-1}\left(\mathrm{XCO}_{2, i}^{m}-\mathrm{XCO}_{2, i}^{\mathrm{obs}}\right) \\
& +\frac{1}{2}\left(s-s_{a}\right) Q_{s}^{-1}\left(s-s_{a}\right),
\end{aligned}
$$

where $\mathrm{N}$ is the total number of satellite-based $\mathrm{XCO}_{2}$ observations. $\mathrm{XCO}_{2}^{m}$ and $\mathrm{XCO}_{2}^{\text {obs }}$ are the modeled and retrieved $\mathrm{XCO}_{2}$, respectively. $s_{a}$ and $s$ are the prior and posterior scaling factors. $R_{\mathrm{obs}}$ is the model-data mismatch error covariance matrix. $Q_{s}$ is the scaling factor error covariance matrix. The $R_{\text {obs }}$ is constructed using the retrieval errors, which are provided along with the TanSat $\mathrm{XCO}_{2}$ data. Following Wang et al. [27], the $Q_{s}$ is constructed using the uncertainties of scaling factors in each grid; meanwhile, a spatial correlation is considered, which is assumed to be decayed exponentially with distance, and the temporal correlation is neglected. The scale lengths assigned along longitudinal and latitudinal directions are 500 and $400 \mathrm{~km}$ for the NEE and 1000 and $800 \mathrm{~km}$ for the ocean exchange, respectively. The prior scaling factor $s_{a}$ is typically set as unity in each month and each grid. The uncertainty of prior scaling factor represents the uncertainty of prior flux, which is assumed to be uniform globally and does not change over time. We followed Deng and Chen [38] to take global annual uncertainties of NEE and ocean flux as $100 \%$ and $40 \%$, respectively, which are the square root of the sum of variances of monthly fluxes at all land and ocean grids, respectively. After a series of testing, the uncertainties of the prior scaling factors for monthly land and ocean fluxes at the grid cell level are calculated to be 3 and 5, respectively. The modeled $\mathrm{XCO}_{2}$ is calculated using the modeled $\mathrm{CO}_{2}$ concentration profile and retrieval averaging kernels according to the following equation:

$$
\mathrm{XCO}_{2}^{m}=\mathrm{XCO}_{2}^{a}+\sum_{j} h_{j} a_{j}\left(A(x)-y_{a, j}\right),
$$

where $j$ denotes the retrieval level. $x$ is the modeled $\mathrm{CO}_{2}$ profile. $A(x)$ is a mapping matrix, which maps the modeled $\mathrm{CO}_{2}$ concentration profile into the satellite retrieval levels. $\mathrm{XCO}_{2}{ }^{a}$ is a prior $\mathrm{XCO}_{2} . h_{j}$ is the pressure weighting function. $a_{j}$ is the satellite averaging kernel. $y_{a}$ is the prior $\mathrm{CO}_{2}$ profile for retrieval.

2.2. TanSat $\mathrm{XCO}_{2}$ Retrievals. We use TanSat $\mathrm{XCO}_{2}$ retrievals produced from the nadir mode measurements by a retrieval scheme based on the IAPCAS retrieval algorithm [23]. It is a joint $\mathrm{CO}_{2}$ weak band and $\mathrm{O}_{2} \mathrm{~A}$ band retrieval. A spectra correction method was developed to remove spectrum artifacts in the fitting residual of the $\mathrm{O}_{2} \mathrm{~A}$ band by applying an 8order Fourier series model. Using $\mathrm{XCO}_{2}$ retrievals from 20 TCCON sites as a reference dataset, a genetic algorithm was applied to select quality filters. The bias correction strategy was constructed from a multiple regression for those selected quality filters. An intercomparison with UoL-FP TanSat $\mathrm{XCO}_{2}$ retrieval indicates a good agreement, with a standard deviation of $1.28 \mathrm{ppm}$ and a bias of $-0.35 \mathrm{ppm}$ [23]. The global transport model we used is unable to resolve the details of individual pixel level retrieval. In addition, individual pixel level retrievals close in time and space are likely to be strongly correlated. Therefore, following Wang et al. [27], we construct a single representative $\mathrm{XCO}_{2}$ value and retrieval error for the model grid cell $\left(4^{\circ} \times 5^{\circ}\right)$ by averaging all $\mathrm{XCO}_{2}$ retrievals and errors falling inside that grid cell. TanSat $\mathrm{XCO}_{2}$ retrievals used in our inversion are over land only and span from 1 March 2017 to 1 May 2018.

2.3. Evaluation Data and Method. The inversion results were independently evaluated by comparing the forwardsimulated $\mathrm{CO}_{2}$ mixing ratios against surface flask measurements of $\mathrm{CO}_{2}$ mixing ratio and TCCON XCO 2 retrievals. The $\mathrm{CO}_{2}$ flask measurements are from the GLOBALVIEWplus v6.0 ObsPack [39], which contains a collection of discrete and quasi-continuous measurements at surface, tower and ship sites contributed by national and universities laboratories around the world. Following the criteria described in Wang et al. [27], we choose flask observations from 52 surface sites among Obspack dataset. TCCON is a network of ground-based Fourier Transform Spectrometers that measure direct near-infrared solar absorption spectra [40]. In this study, we use $\mathrm{XCO}_{2}$ retrievals from 26 stations from TCCON GGG2014R1 dataset [41-67]. The locations of the flask and TCCON sites used in this study are shown in Figure 1.

We run the GEOS-Chem model with both prior and posterior fluxes to obtain their corresponding $\mathrm{CO}_{2}$ mixing ratios. The simulated $\mathrm{CO}_{2}$ mixing ratios are sampled at flask site location and within half an hour of observation time. For the comparisons with TCCON retrievals, we firstly mapped the simulated prior and posterior $\mathrm{CO}_{2}$ concentrations at 47 model levels into 71 TCCON levels, and then, calculated the modeled $\mathrm{XCO}_{2}$ values at those TCCON sites according to the approach of Wunch et al. [40]. Mean biases and standard deviation of the biases (STDEV) between the modeled and observed $\mathrm{CO}_{2}$ mixing ratios and $\mathrm{XCO}_{2}$ were calculated to evaluate the inversion results.

\section{Results and Discussions}

3.1. Global Carbon Budget. Table 1 presents the prior and posterior $\mathrm{CO}_{2}$ fluxes, which are globally aggregated over land and oceans for the period from Apr 2017 to Mar 2018. The optimized global NEE and ocean flux for the 1year period are $-3.46 \mathrm{PgC}$ and $-2.77 \mathrm{PgC}$, respectively. With 10.0 PgC from fossil fuel and cement production and $2.40 \mathrm{PgC}$ from biomass burning released into the atmosphere, the inversion estimates that the global net carbon flux is $6.15 \mathrm{PgC}$. During this 1 -year period, the global mean atmospheric $\mathrm{CO}_{2}$ mixing ratio estimated by NOAA/ESRL increases by $2.46 \mathrm{ppm}$ (Ed Dlugokencky and Pieter Tans, NOAA/ESRL, http://www.esrl.noaa.gov/gmd/ccgg/trends/), which is the equivalent of a net carbon increase of $5.2 \mathrm{PgC}$ in the atmosphere [68]. The global mean atmospheric 


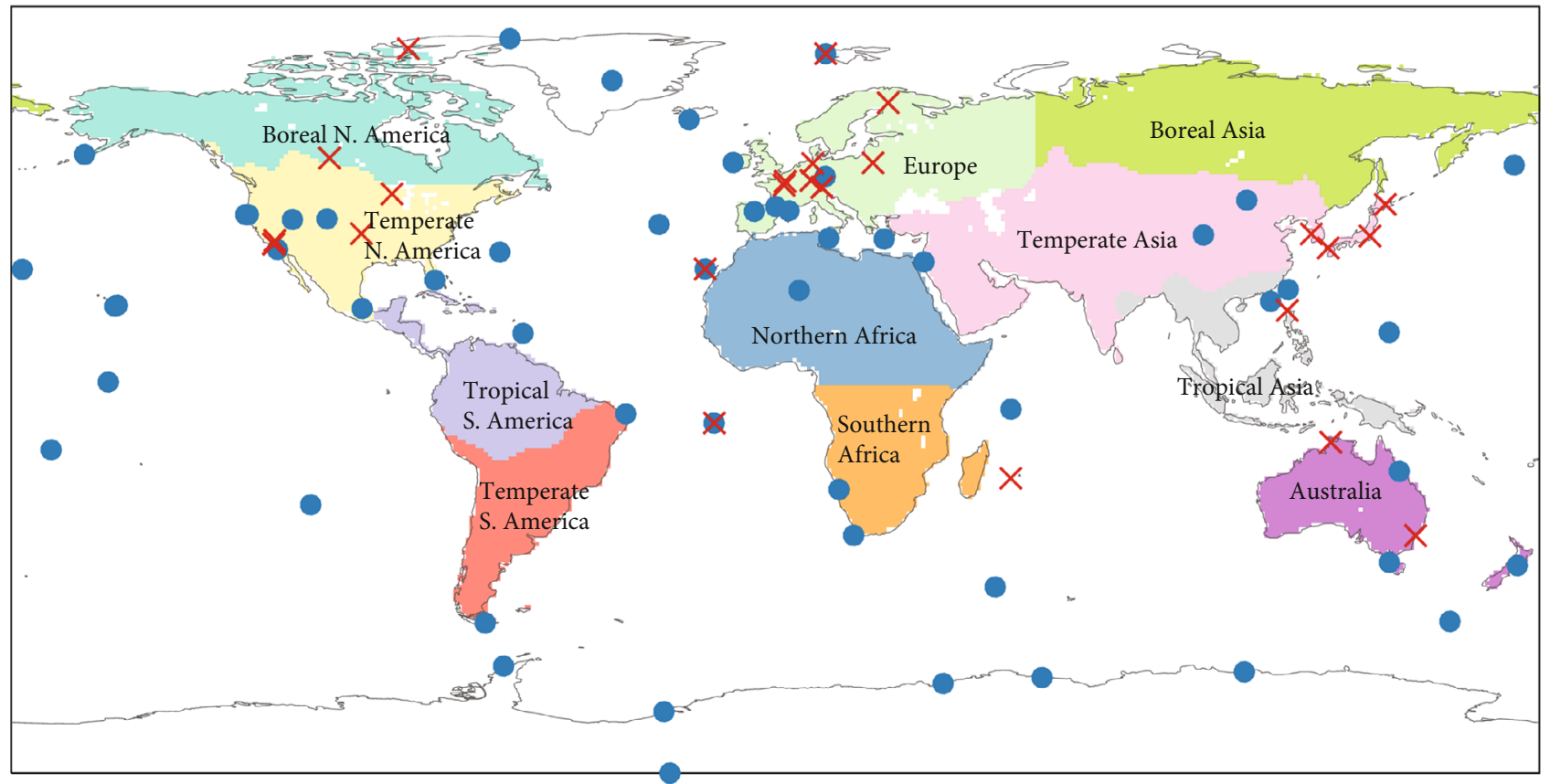

FIGURE 1: Distributions of the observation sites used in this study. Solid circles are surface flask sites, red cross marks are TCCON sites, the shaded area shows the 11 TRANSCOM regions.

TABle 1: Global carbon budget from Apr 2017 to Mar 2018 $\left(\mathrm{PgC} \mathrm{yr}^{-1}\right)$.

\begin{tabular}{lccccc}
\hline & $\begin{array}{c}\text { Fossil fuel and } \\
\text { cement } \\
\text { production }\end{array}$ & $\begin{array}{c}\text { Biomass } \\
\text { burning }\end{array}$ & NEE & $\begin{array}{c}\text { Ocean } \\
\text { flux }\end{array}$ & $\begin{array}{c}\text { Global } \\
\text { net flux }\end{array}$ \\
\hline $\begin{array}{l}\text { Prior flux } \\
\text { Posterior }\end{array}$ & 10.0 & 2.40 & -2.98 & -2.84 & 6.58 \\
flux & & & -3.46 & -2.77 & 6.15 \\
\hline
\end{tabular}

growth rate (AGR) reflects well the total net $\mathrm{CO}_{2}$ flux added into the atmosphere. On global scale, the uncertainties of carbon emissions from fossil fuel and cement production $\left(E_{\mathrm{ff}}\right)$ and biomass burning $\left(E_{\mathrm{bb}}\right)$ are relatively small; thus, the global total land and ocean sinks can be estimated directly $\left(E_{\mathrm{ff}}+E_{\mathrm{bb}}-\mathrm{AGR}\right)$, which is generally used as a benchmark to evaluate the global inversion results. The posterior total sink of land and ocean is larger than the prior sink (see Table 1), but it is still lower than the benchmark, indicating that the inversion using TanSat $\mathrm{XCO}_{2}$ albeit improves to some extent compared to the prior, but still underestimates the total land and ocean $\mathrm{CO}_{2}$ sink to a certain extent. The differences of ocean fluxes between the prior and the posterior flux are small since the TanSat $\mathrm{XCO}_{2}$ retrievals are only available over land.

3.2. Regional Carbon Flux. Figure 2 shows the distributions of annual posterior and prior land and ocean carbon fluxes for the 1-year period (excluding the carbon emissions from fossil fuel combustion, cement production, and biomass burning). Compared with the prior flux, the posterior land sinks increase significantly in most part of Eurasia boreal region, eastern part of China, western part of North America boreal region, and midwestern and eastern regions of the USA. Contrastingly, the inferred land sinks decrease remarkably in Africa, Latin America, and India peninsula (Figure 2(c)) and even turn to significant carbon sources in Sahel, eastern Africa and India peninsula (Figure 2(a)).

Table 2 summarizes the annually aggregated NEE in China, the 11 TRANSCOM land regions, and the regions of different latitudes. Our inversion estimates most land regions in Northern Hemisphere as strong carbon sinks. Especially in Europe and boreal Asia, the prior flux shows weak carbon sinks, while the posterior flux presents strong sinks up to 1.25 and $1.1 \mathrm{PgC}$, respectively. The difference between posterior and prior flux in tropical Asia is small since there are few satellite observations over this region. Most noticeably, the inversion gives northern Africa as a relatively large carbon source of $1.53 \mathrm{PgC}$. In Southern Hemisphere, southern Africa and temperate S. America also have obvious reductions of carbon sinks, with NEE decreasing from -0.55 and -0.42 to -0.05 and $-0.26 \mathrm{PgC} \mathrm{yr}^{-1}$, respectively, while the NEE in Australia shifts to a weak carbon sink. Using the same TanSat $\mathrm{XCO}_{2}$ retrievals to infer the net carbon budget over land without differentiating biosphere flux from other components, Yang et al. [26] also found large reductions of carbon flux in northern mid-tohigh latitudes and strong enhancements of carbon flux in tropical S. America and Africa compared to prior flux. Since different inversion methods and settings were applied, this similar flux adjustment pattern between two inversions is likely induced by TanSat $\mathrm{XCO}_{2}$ retrievals.

Our estimated land sinks in temperate N. America $\left(-0.71 \mathrm{PgC} \mathrm{yr}^{-1}\right)$ and temperate Asia $\left(-0.50 \mathrm{PgC} \mathrm{yr}^{-1}\right)$ are in 


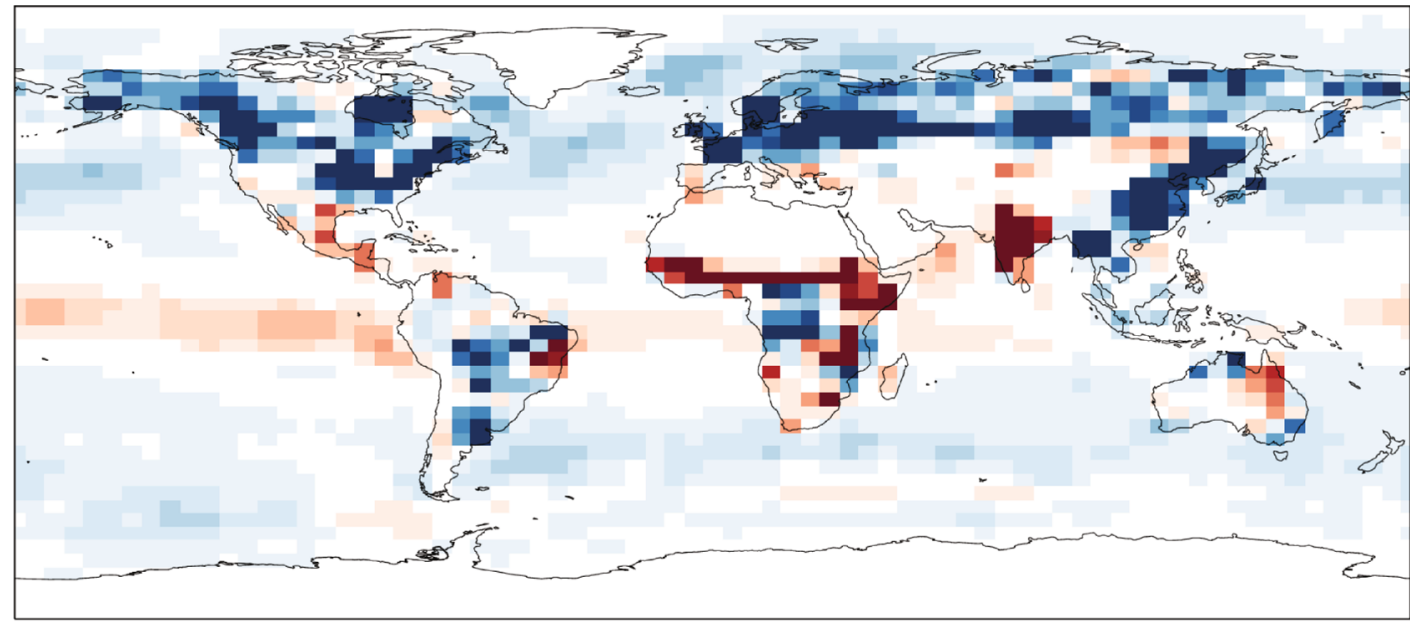

$\mathrm{gC} \mathrm{m}^{-2} \mathrm{yr}^{-1}$

(a)

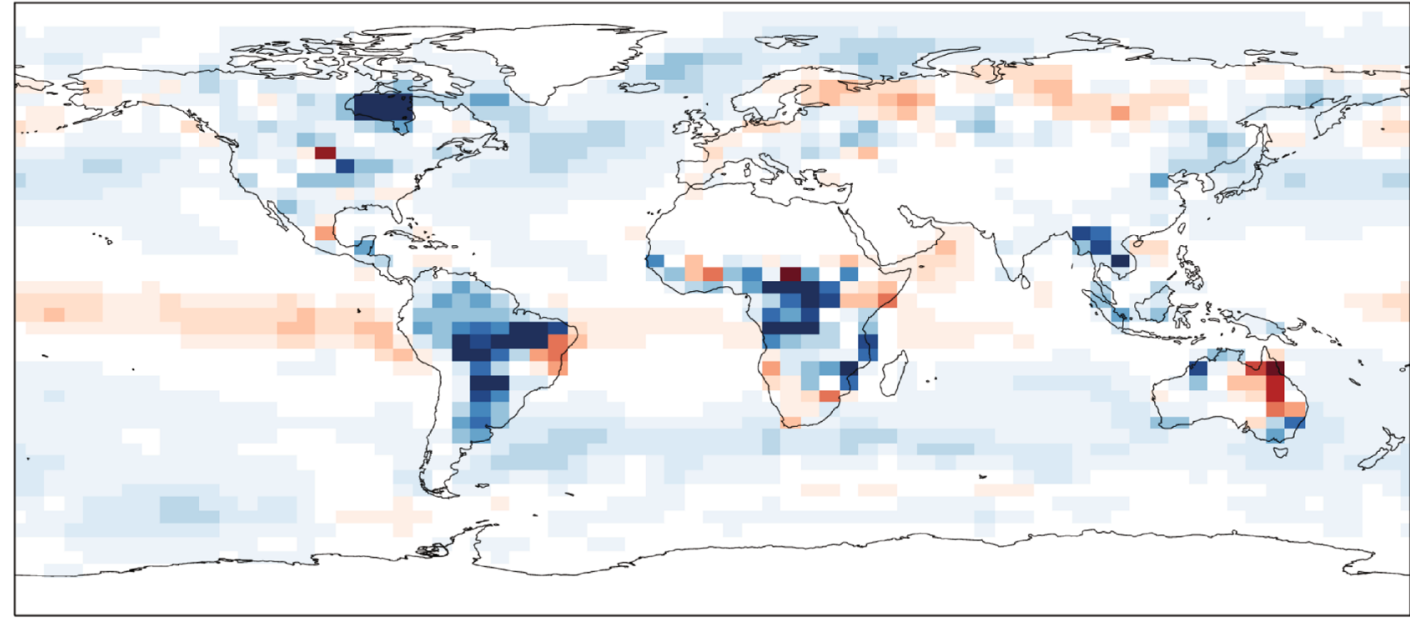

(b)

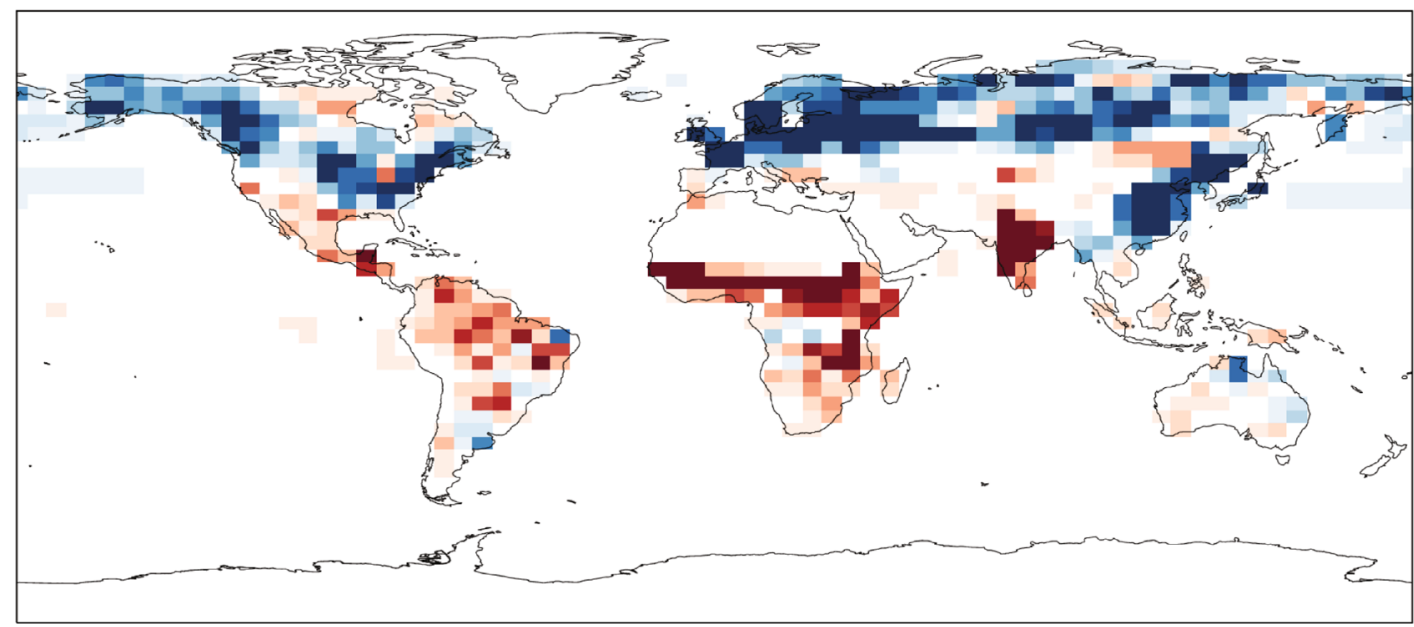

(c)

Figure 2: Global distributions of (a) the posterior flux, (b) the prior flux, and (c) the differences between posterior and prior fluxes.

the range of previous inverse modeling studies of $-0.5 \sim-$ $0.9 \mathrm{PgC} \mathrm{yr}^{-1}[27,31,69-71]$ and $-0.4 \sim-0.7 \mathrm{PgC} \mathrm{yr}^{-1}[27,31$, $69,70,72]$, respectively. In Europe, the carbon sink is significantly stronger than those from recent EUROCOM inversions using surface in situ observations [73], but close to those from the inversions using an earlier version of GOSAT $\mathrm{XCO}_{2}$ retrievals $[7,69]$. In China, although the carbon sink is two times higher than a previous comprehensive estimate based on both top-down and bottom-up approaches [74], it is lower than that from a most recent inversion using 
TABLE 2: The prior and posterior carbon fluxes in different regions $\left(\mathrm{PgC} \mathrm{yr}^{-1}\right)$.

\begin{tabular}{lcc}
\hline Regions & Prior & Posterior \\
\hline China & -0.15 & -0.95 \\
Boreal N. America & -0.10 & -0.55 \\
Temperate N. America & -0.23 & -0.71 \\
Boreal Asia & -0.05 & -1.10 \\
Temperate Asia & -0.22 & -0.50 \\
Tropical Asia & -0.34 & -0.35 \\
Europe & -0.03 & -1.25 \\
Tropical S. America & -0.70 & -0.17 \\
Temperate S. America & -0.42 & -0.26 \\
Northern Africa & -0.34 & 1.53 \\
Southern Africa & -0.55 & -0.05 \\
Australia & 0.00 & -0.04 \\
Northern boreal land & -0.15 & -1.65 \\
Northern temperate land & -0.48 & -2.46 \\
Tropical land & -1.38 & 1.01 \\
Southern temperate land & -0.97 & -0.35 \\
\hline
\end{tabular}

China's surface in situ $\mathrm{CO}_{2}$ measurements [75]. In boreal lands, our estimated sinks are stronger than previous studies, especially in boreal Asia, where previous studies showed a moderate sink in the range of -0.11 to $-0.76 \mathrm{PgC} \mathrm{yr}^{-1}[70$, 76-79]. In tropical and southern lands, the inverted NEE in S. America, Australia, and tropical Asia are roughly close to those from previous studies [70], but the inverted NEE in Africa has a great difference from previous studies. For example, Ciais et al. [80] presented a synthesis of estimates for Africa's carbon balance, giving a sink of $-0.2 \mathrm{PgC} \mathrm{yr}^{-1}$ (excluding land use change emissions), and CarbonTracker inversions usually show a stronger sink in the range of $-0.6 \sim-1.4 \mathrm{PgC} \mathrm{yr}^{-1}$ [31]. It is worth mentioning that, compared to the previous studies, we here just present 1-year estimates which can be largely influenced by climate interannual variability [81-83].

This flux change pattern derived from TanSat $\mathrm{XCO}_{2}$, of apparent strengthening of carbon sinks in northern midto-high latitudes and weakening in tropical and southern lands, is also not consistent with our previous inverse modeling using the same system with GOSAT and OCO-2 $\mathrm{XCO}_{2}$ retrievals [27]. To further understand how prior flux was adjusted by TanSat data, we examine the seasonal variations of prior and posterior fluxes as shown in Figure 3. In temperate and boreal land regions, posterior fluxes are generally in phase with prior fluxes in growing season, with small adjustment of prior flux in Europe and N. America and apparent enhancement of carbon uptake in Eurasia region. However, starting from November 2017, posterior fluxes in all these regions decrease gradually; namely, the nongrowing season carbon release exhibits relatively large reduction. It is difficult to find an ecological answer for this apparent decrease of nongrowing season carbon release across northern mid-to-high latitudes. Most likely, after
November 2017, the TanSat $\mathrm{XCO}_{2}$ retrievals possess systematic negative biases, resulting in an underestimate of carbon release in these regions.

In tropical regions and Southern Africa, except tropical Asia, the posterior fluxes are also in phase with the prior flux, but the posterior fluxes have stronger carbon release basically throughout the year. For tropical Asia and Australia, the adjustment of prior flux made by TanSat $\mathrm{XCO}_{2}$ is not significant. In temperate $\mathrm{S}$. America, the posterior flux is out of phase with the prior flux, with carbon release peak in November other than in May as of prior flux. Compared to the seasonal cycles recovered by the other systems like CT [31], CMS-Flux [84], and GCASv2 [70], the changes of monthly NEE constrained by TanSat $\mathrm{XCO}_{2}$ adjust the seasonal cycles in temperate S. America, tropical S. America, and Southern Africa much closer to the previous estimates. In Northern Africa, although the seasonal cycles of the posterior fluxes are basically the same as those of the prior fluxes, except for the weak carbon sinks in September and October, the remaining months are all carbon sources in the posterior fluxes. Palmer et al. [85] showed that even in extremely dry years $(2015 / 16)$, there are strong sink during the wet seasons. Liu et al. [84] showed the multiyear (2010-2017) averaged seasonal cycles of net biosphere exchange (NBE, including biomass burning carbon emissions) in Northern Africa from 4 inversion systems (e.g., CAMS, CT-Europe, CarboScope, and CMS-Flux). All the 4 systems show significant sinks in this area. Therefore, we believe that the posterior monthly fluxes in Northern Africa in this study are unreasonable.

3.3. Evaluation for the Inversion Results. As shown in Table 3, the mean bias between the prior $\mathrm{CO}_{2}$ mixing ratio and flask measurements is $0.97 \mathrm{ppm}$, with a standard deviation of $2.19 \mathrm{ppm}$, while the mean biases between the posterior $\mathrm{CO}_{2}$ mixing ratio and flask measurements are reduced to $0.08 \mathrm{ppm}$, with a standard deviation of $2.24 \mathrm{ppm}$. The reduction of overall posterior bias relative to the prior bias suggests that the inversion improves the global estimate of total carbon sink, while the slight increase of posterior STDEV relative to the prior one shows that the inversion has not improved carbon flux estimates consistently at regional scales. At TCCON sites, the overall bias and STDEV of the $\mathrm{XCO}_{2}$ simulated using the posterior flux are both reduced. The posterior $\mathrm{XCO}_{2}$ yields a smaller STDEV of the differences, which is not surprising since the TanSat $\mathrm{XCO}_{2}$ retrievals were bias corrected using the TCCON retrievals.

Figure 4 depicts the biases at each flask and TCCON site in their corresponding latitude. For most of flask sites, prior $\mathrm{CO}_{2}$ mixing ratios have positive biases, indicating the prior flux underestimate carbon sinks in both Northern and Southern Hemisphere. As for posterior $\mathrm{CO}_{2}$ mixing ratios, the biases become larger at sites in Southern Hemisphere and tropical regions and turn to relatively large negative value at sites in northern high-latitude $\left(>40^{\circ} \mathrm{N}\right)$ regions, while in northern middle-latitude $\left(10^{\circ} \mathrm{N}\right.$ to $\left.40^{\circ} \mathrm{N}\right)$ regions, the biases are significantly reduced. This suggests that the inversion underestimates carbon sinks in Southern 


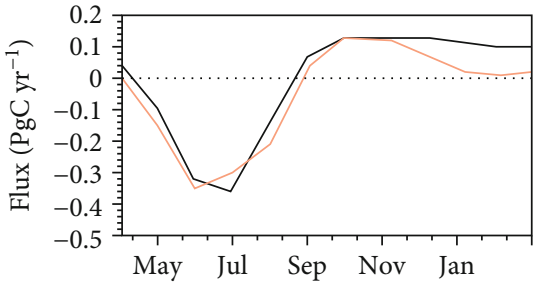

(a) Boreal N. America

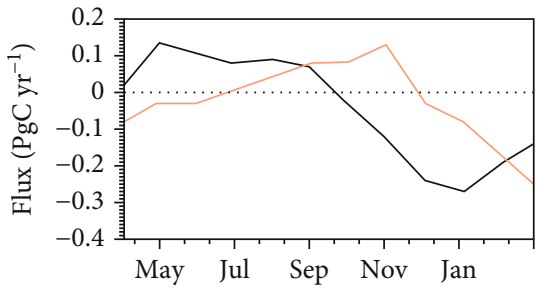

(d) Temperate S. America

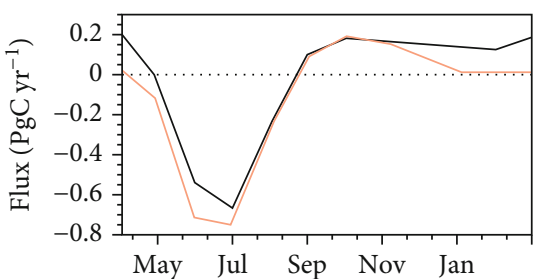

(g) Boreal Asia

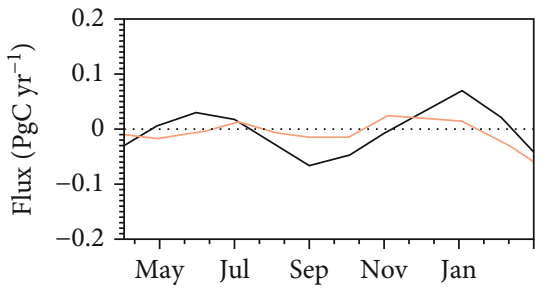

(j) Australia

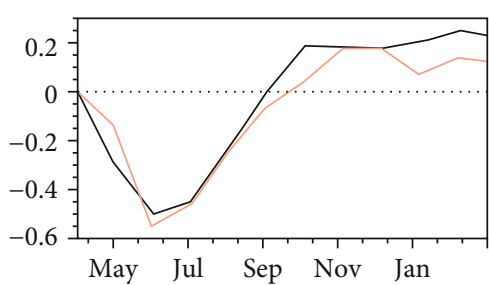

(b) Temperate N. America

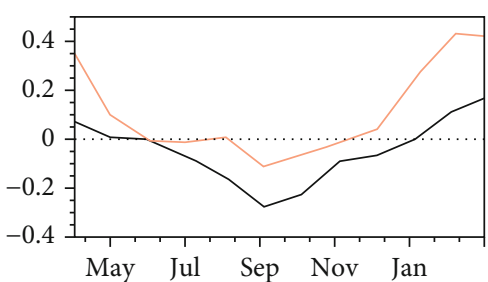

(e) Northern Africa

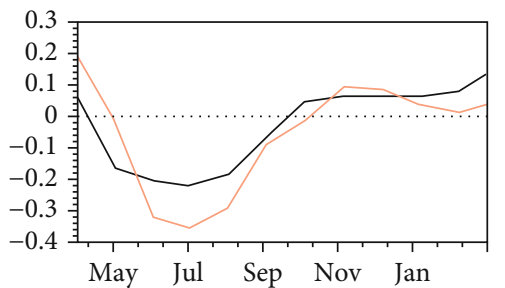

(h) Temperate Asia

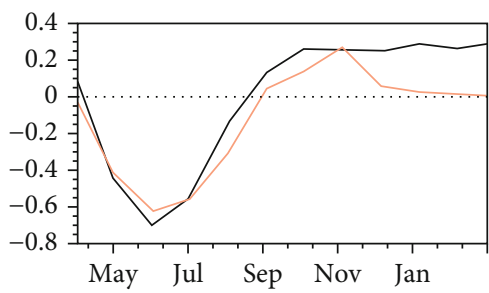

(k) Europe

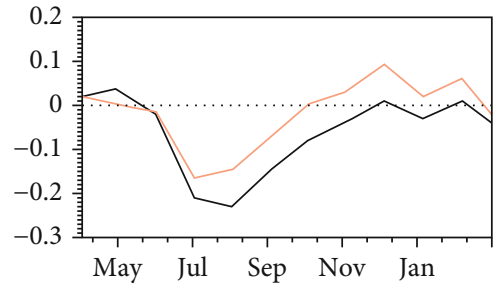

(c) Tropical S. America

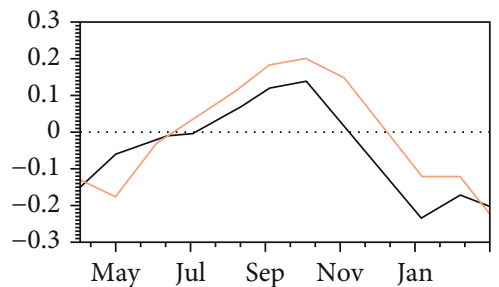

(f) Southern Africa

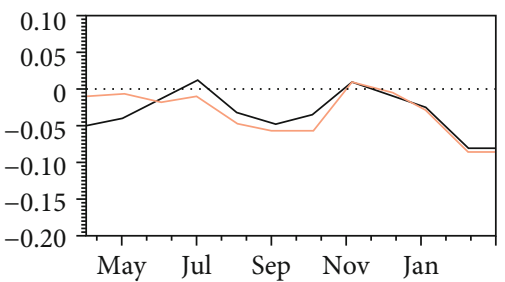

(i) Tropical Asia

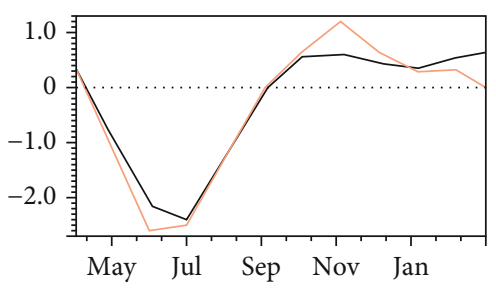

(l) Global land

Prior

Posterior

FIGURE 3: Seasonal variations of the prior and posterior fluxes in 11 TRANSCOM regions and all lands.

TABLE 3: Statistics of the model-data mismatches at the 52 surface flask sites and the 26 TCCON sites (ppm).

\begin{tabular}{lcccc}
\hline & \multicolumn{2}{c}{ Flask } & \multicolumn{2}{c}{ TCCON } \\
& Prior & Posterior & Prior & Posterior \\
\hline Bias & 0.97 & 0.08 & 0.89 & 0.17 \\
St. dev. & 2.19 & 2.24 & 1.75 & 1.48 \\
\hline
\end{tabular}

Hemisphere and tropical regions, overestimates the carbon sinks significantly in northern high-latitude regions, and improves the estimates of NEE in northern middlelatitude regions. The latitudinal distributions of the mean biases of the prior and posterior $\mathrm{XCO}_{2}$ at the TCCON sites located in Southern Hemisphere and northern middle and low latitudes are very similar to those at flask sites, while in northern high latitudes, the posterior matches well with TCCON but shows a large negative bias in respective to flasks. The different performances of the posterior concentrations against flask and TCCON observations in northern high latitudes may be related to the simulations of vertical $\mathrm{CO}_{2}$ profile in these areas, which should be paid attention to in the future. The biases of prior $\mathrm{XCO}_{2}$ are positive at most of the TCCON sites. Relative to the prior $\mathrm{XCO}_{2}$, the bias of posterior $\mathrm{XCO}_{2}$ becomes larger in Southern Hemisphere and tropical regions. In northern mid- to highlatitude regions, overall, though positive biases of posterior $\mathrm{XCO}_{2}$ at 16 sites are greatly reduced and fall within -0.8 to $0.8 \mathrm{ppm}$ interval, there are still 4 sites with relatively large negative bias. Evaluation results at TCCON sites are in general comparable to those at surface flask sites, further suggesting the underestimation of carbon flux in Southern Hemisphere and tropical regions and improvement of the carbon sinks in northern middle-latitude regions.

Overall, the overestimation of carbon sinks in high latitudes implies that the TanSat $\mathrm{XCO}_{2}$ retrievals have systematic negative biases over this region, while the 


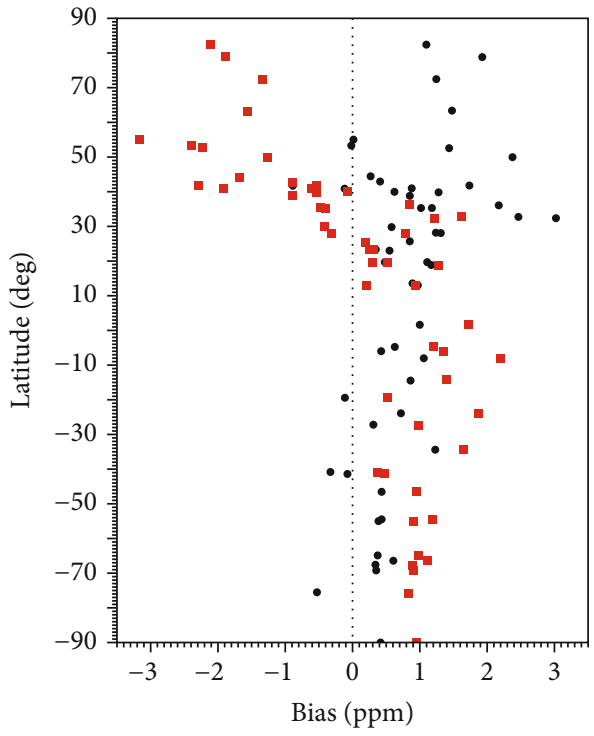

(a)

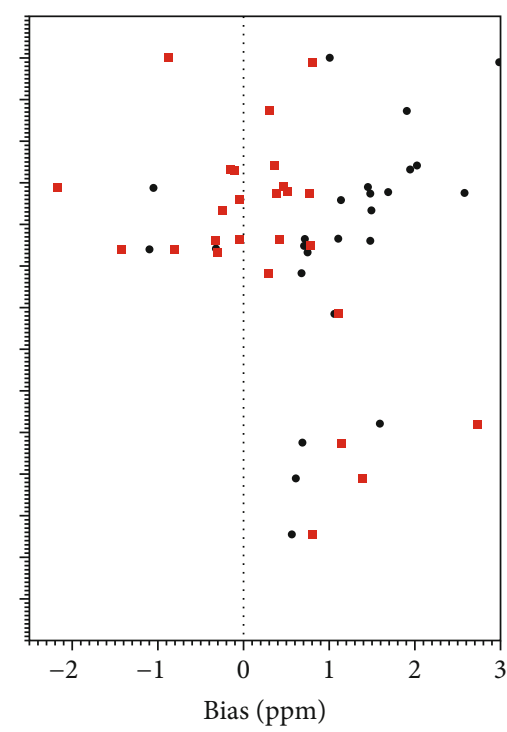

(b)

- Prior

Posterior

FIGURE 4: Biases of the simulated $\mathrm{CO}_{2}$ mixing ratios against (a) the flask measurements and (b) the TCCON XCO 2 retrievals in different latitudes (bias equals modeled minus observed).

underestimates of carbon sinks in Southern Hemisphere and tropical regions indicate the systematic positive biases.

\section{Conclusions}

In this study, based on the GEOS-Chem 4D-Var data assimilation system, we use TanSat $\mathrm{XCO}_{2}$ retrievals to constrain terrestrial NEE from April 2017 to March 2018. The annual and monthly posterior NEE at both global and regional scales are shown and discussed. The posterior carbon fluxes are evaluated by comparing the posterior $\mathrm{CO}_{2}$ mixing ratios against observations from 52 surface flask sites and 26 TCCON sites.

The inversion estimates global land carbon sink at $-3.46 \mathrm{PgC} \mathrm{yr}^{-1}$, evidently higher than prior estimate and giving rise to an improved estimate of global atmospheric $\mathrm{CO}_{2}$ growth rate. Regionally, in northern mid-high latitudes, the land sinks were greatly increased, while in tropical and southern lands, carbon sinks were significantly reduced, and even turned into carbon sources, especially over Africa and India peninsula. In northern lands, the enhancement of posterior carbon sinks is mainly attributed to the decreased carbon release during the nongrowing season, and in tropical and southern lands, the decrease of carbon uptake or increase of carbon release basically occurs throughout the year.

Evaluations of the inversions using $\mathrm{CO}_{2}$ concentrations from flask measurements and TCCON retrievals show that the inversion overestimates the land sinks in northern high-latitude regions, significantly underestimates those in tropical and southern lands, and improves the NEE in the northern middle-latitude regions to a certain extent. These suggest that TanSat $\mathrm{XCO}_{2}$ still have systematic negative biases in northern high-latitude regions and positive biases over tropical and southern lands, especially in Northern Africa. These systematic biases are probably caused by the bias correction process of the TanSat $\mathrm{XCO}_{2}$ retrievals. Generally, the bias correction strategy removes parameterdependent biases using a linear combination of identified bias parameters such as $\mathrm{CO}_{2}$ gradient between $700 \mathrm{hPa}$ and surface, surface pressure difference between prior and retrieval, and surface albedo of $\mathrm{CO}_{2}$ weak band. The coefficients are determined by the linear regression of differences between TanSat $\mathrm{XCO}_{2}$ and TCCON measurements and those parameters. Since most of TCCON sites are located in northern middle latitudes (Figure 1), the obtained coefficients work well to remove bias in those regions. However, there are fewer TCCON sites in northern high latitudes and tropical and southern land; the regression relationship obtained in northern middle latitudes might not hold well in those regions; thus, the bias correction process might not remove biases effectively and even produce more biases.

Effective bias correction is critical for the quality of $\mathrm{XCO}_{2}$ data. The TCCON-based bias correction needs to be complemented with using other sources such as small area approximation and model-based truth proxies as adopted by OCO-2 products [86]. Effort should be dedicated to develop new truth proxies since the combination of aforementioned sources is still not adequate. A more complete bias correction scheme could not only further improve the accuracy of current TanSat retrievals but also facilitate the development of retrieval algorithm for China's planned carbon satellite missions as well. 


\section{Data Availability}

The global terrestrial ecosystem carbon flux inferred in this study is free to access at doi:10.5281/zenodo.5720212. The TanSat v2 $\mathrm{XCO}_{2}$ data product can be obtained from the CASA TanSat data and science service (http://www .chinageoss.cn/tansat/index.html).

\section{Conflicts of Interest}

The authors declare that there is no conflict of interest regarding the publication of this article.

\section{Authors' Contributions}

Hengmao Wang conducted the inversion and wrote the draft. Fei Jiang designed the experiment and revised the manuscript. Yi Liu, Dongxu Yang, and Jing Wang provided the TanSat $\mathrm{XCO}_{2}$ data and helped to revise the manuscript. Mousong Wu, Wei He, Jun Wang, Weimin Ju, and Jing M. Chen provided important comments and revised the manuscript.

\section{Acknowledgments}

This work is supported by the National Key R\&D Program of China (Grant Nos. 2016YFA0600204 and SQ2019YFE0 13078), the National Natural Science Foundation of China (Grant Nos. 41807434 and 41907378), and the Key Research Program of the Chinese Academy of Sciences (ZDRW-ZS2019-1). We acknowledge all atmospheric data providers to obspack_co2_1_GLOBALVIEWplus_v6.0_2020-09-11. The TCCON data were obtained from the TCCON Data Archive hosted by CaltechDATA at https://tccondata.org. The CarbonTracker CT2019 results are provided by NOAA ESRL, Boulder, Colorado, USA, from the website at http:// carbontracker.noaa.gov. We are also grateful to the HighPerformance Computing Center (HPCC) of Nanjing University for doing the numerical calculations in this paper on its blade cluster system. The TanSat data product service is provided by IRCSD and CASA (131211KYSB20180002).

\section{References}

[1] A. Kuze, H. Suto, M. Nakajima, and T. Hamazaki, "Thermal and near infrared sensor for carbon observation Fouriertransform spectrometer on the greenhouse gases observing satellite for greenhouse gases monitoring," Applied Optics, vol. 48, no. 35, pp. 6716-6733, 2009.

[2] D. Crisp, H. R. Pollock, R. Rosenberg et al., "The on-orbit performance of the Orbiting Carbon Observatory-2 (OCO-2) instrument and its radiometrically calibrated products," Atmospheric Measurement Techniques, vol. 10, no. 1, pp. 59-81, 2017.

[3] A. Eldering, P. O. Wennberg, D. Crisp et al., "The Orbiting Carbon Observatory-2 early science investigations of regional carbon dioxide fluxes," Science, vol. 358, no. 6360, article eaam5745, 2017.

[4] D. Yang, Y. Liu, Z. N. Cai, X. Chen, L. Yao, and D. Lu, "First global carbon dioxide maps produced from TanSat measure- ments," Advances in Atmospheric Sciences, vol. 35, no. 6, pp. 621-623, 2018.

[5] M. Nakajima, M. Hashimoto, M. Sakai et al., "Results of the commissioning phase of the mission instruments on GOSAT-2," in Sensors, Systems, and Next-Generation Satellites XXIII, no. article 1115103, 2019International Society for Optics and Photonics, 2019.

[6] A. Eldering, T. E. Taylor, C. W. O'Dell, and R. Pavlick, "The OCO-3 mission: measurement objectives and expected performance based on 1 year of simulated data," Atmospheric Measurement Techniques, vol. 12, no. 4, pp. 2341-2370, 2019.

[7] S. Basu, S. Guerlet, A. Butz et al., "Global $\mathrm{CO}_{2}$ fluxes estimated from GOSAT retrievals of total column $\mathrm{CO}_{2}$," Atmospheric Chemistry and Physics, vol. 13, no. 17, pp. 8695-8717, 2013.

[8] F. Chevallier, P. I. Palmer, L. Feng, H. Boesch, C. W. O'Dell, and P. Bousquet, "Toward robust and consistent regional CO2flux estimates from in situ and spaceborne measurements of atmospheric $\mathrm{CO}_{2}$," Geophysical Research Letters, vol. 41, no. 3, pp. 1065-1070, 2014.

[9] J. Heymann, M. Reuter, M. Buchwitz et al., "CO2emission of Indonesian fires in 2015 estimated from satellite-derived atmospheric CO2concentrations," Geophysical Research Letters, vol. 44, no. 3, pp. 1537-1544, 2017.

[10] S. Houweling, D. Baker, S. Basu et al., "An intercomparison of inverse models for estimating sources and sinks of CO2using GOSAT measurements," Journal of Geophysical Research: Atmospheres, vol. 120, no. 10, pp. 5253-5266, 2015.

[11] C. Lin, C. L. Li, L. Wang, Y. Bi, and Y. Zheng, "Preflight spectral calibration of hyperspectral carbon dioxide spectrometer of TanSat (in Chinese)," Optics and Precision Engineering, vol. 25, no. 8, pp. 2064-2075, 2017.

[12] S. Maksyutov, H. Takagi, V. K. Valsala et al., "Regional $\mathrm{CO}_{2}$ flux estimates for 2009-2010 based on GOSAT and groundbased $\mathrm{CO}_{2}$ observations," Atmospheric Chemistry and Physics, vol. 13, no. 18, pp. 9351-9373, 2013.

[13] P. K. Patra, D. Crisp, J. W. Kaiser et al., "The Orbiting Carbon Observatory (OCO-2) tracks 2-3 peta-gram increase in carbon release to the atmosphere during the 2014-2016 El Niño," Scientific reports, vol. 7, no. 1, article 13567, 2017.

[14] M. Reuter, M. Buchwitz, M. Hilker et al., "Satellite-inferred European carbon sink larger than expected," Atmospheric Chemistry and Physics, vol. 14, no. 24, pp. 13739-13753, 2014.

[15] J. Liu, K. W. Bowman, D. S. Schimel et al., "Contrasting carbon cycle responses of the tropical continents to the 2015-2016 El Niño," Science, vol. 358, no. 6360, article eaam5690, 2017.

[16] M. Reuter, M. Buchwitz, O. Schneising et al., “Towards monitoring localized $\mathrm{CO}_{2}$ emissions from space: co-located regional $\mathrm{CO}_{2}$ and $\mathrm{NO}_{2}$ enhancements observed by the OCO-2 and S5P satellites," Atmospheric Chemistry and Physics, vol. 19, no. 14, pp. 9371-9383, 2019.

[17] R. Nassar, T. G. Hill, M. L. CA, D. Wunch, D. B. Jones, and D. Crisp, "Quantifying $\mathrm{CO}_{2}$ emissions from individual power plants from space," Geophysical Research Letters, vol. 44, pp. 10045-10053, 2017.

[18] B. Zheng, F. Chevallier, P. Ciais et al., "Observing carbon dioxide emissions over China's cities and industrial areas with the Orbiting Carbon Observatory-2," Atmospheric Chemistry and Physics, vol. 20, no. 14, pp. 8501-8510, 2020.

[19] W. Chen, Y. Zhang, Z. Yin et al., "The TanSat mission: global $\mathrm{CO}_{2}$ observation and monitoring," in Proceedings of the 63rd 
IAC (International Astronautical Congress), Naples, Italy, 2012.

[20] Y. Ran and X. Li, "TanSat: a new star in global carbon monitoring from China," Science Bulletin, vol. 64, no. 5, pp. 284-285, 2019.

[21] H. Zhang, Y. Zheng, S. Li et al., "Geometric correction for TanSat atmospheric carbon dioxide grating spectrometer," Sensors and Actuators, A: Physical, vol. 293, pp. 62-69, 2019.

[22] D. Yang, H. Boesch, Y. Liu et al., "Toward high precision $\mathrm{XCO}_{2}$ retrievals from TanSat observations: retrieval improvement and validation against TCCON measurements," Journal of Geophysical Research: Atmospheres, vol. 125, article e2020JD032794, 2020.

[23] D. Yang, Y. Liu, H. Boesch et al., "A new TanSat $\mathrm{XCO}_{2}$ global product towards climate studies," Advances in Atmospheric Sciences, vol. 38, no. 1, pp. 8-11, 2021.

[24] S. Wang, R. van der A, P. Stammes et al., "Carbon dioxide retrieval from TanSat observations and validation with TCCON measurements," Remote Sensing, vol. 12, no. 14, article 2204, 2020.

[25] X. Hong, P. Zhang, Y. Bi et al., "Retrieval of global carbon dioxide from TanSat satellite and comprehensive validation with TCCON measurements and satellite observations," IEEE Transactions on Geoscience and Remote Sensing, vol. 60, pp. 1$16,2022$.

[26] D. Yang, Y. Liu, L. Feng et al., "The first global carbon dioxide flux map derived from TanSat measurements," Advances in Atmospheric Sciences, vol. 38, no. 9, pp. 1433-1443, 2021.

[27] H. M. Wang, F. Jiang, J. Wang, W. Ju, and J. M. Chen, “Terrestrial ecosystem carbon flux estimated using GOSAT and $\mathrm{OCO}_{2}$ retrievals," Atmospheric Chemistry and Physics, vol. 19, no. 18, pp. 12067-12082, 2019.

[28] I. Bey, D. J. Jacob, R. M. Yantosca et al., "Global modeling of tropospheric chemistry with assimilated meteorology: model description and evaluation," Journal of Geophysical Research, vol. 106, no. D19, pp. 23073-23095, 2001.

[29] P. Suntharalingam, D. J. Jacob, P. I. Palmer et al., "Improved quantification of Chinese carbon fluxes using $\mathrm{CO}_{2} / \mathrm{CO}$ correlations in Asian outflow," Journal of Geophysical Research, vol. 109, no. D18, article D18S18, 2004.

[30] R. Nassar, D. B. A. Jones, P. Suntharalingam et al., "Modeling global atmospheric $\mathrm{CO}_{2}$ with improved emission inventories and $\mathrm{CO}_{2}$ production from the oxidation of other carbon species," Geoscientific Model Development, vol. 3, no. 2, pp. 689716, 2010.

[31] A. R. Jacobson, K. N. Schuldt, J. B. Miller et al., "CarbonTracker CT2019," in NOAA Earth System Research Laboratory, Global Monitoring Division, Boulder, CO, USA, 2020.

[32] D. K. Henze, A. Hakami, and J. H. Seinfeld, "Development of the adjoint of GEOS-Chem," Atmospheric Chemistry and Physics, vol. 7, no. 9, pp. 2413-2433, 2007.

[33] R. J. Andres, J. S. Gregg, L. Losey, G. Marland, and T. A. Boden, "Monthly, global emissions of carbon dioxide from fossil fuel consumption," Tellus B, vol. 63, no. 3, pp. 309-327, 2011.

[34] T. Oda, S. Maksyutov, and R. J. Andres, "The Open-source Data Inventory for Anthropogenic $\mathrm{CO}_{2}$, version 2016 (ODIAC2016): a global monthly fossil fuel $\mathrm{CO}_{2}$ gridded emissions data product for tracer transport simulations and surface flux inversions," Earth System Science Data, vol. 10, no. 1, pp. 87-107, 2018.
[35] I. R. van der Velde, J. B. Miller, K. Schaefer, G. R. van der Werf, M. C. Krol, and W. Peters, "Terrestrial cycling of ${ }^{13} \mathrm{CO}_{2}$ by photosynthesis, respiration, and biomass burning in SiBCASA," Biogeosciences, vol. 11, no. 23, pp. 6553-6571, 2014.

[36] J. T. Randerson, G. R. van der Werf, L. Giglio, G. J. Collatz, and P. S. Kasibhatla, Global Fire Emissions Database, Version 4.1 (GFEDv4), ORNL DAAC, Oak Ridge, Tennessee, USA, 2017.

[37] C. Rödenbeck, R. F. Keeling, D. C. E. Bakker et al., "Global surface-ocean $\mathrm{pCO}_{2}$ and sea-air $\mathrm{CO}_{2}$ flux variability from an observation-driven ocean mixed-layer scheme," Ocean Science, vol. 9, no. 2, pp. 193-216, 2013.

[38] F. Deng and J. M. Chen, "Recent global $\mathrm{CO}_{2}$ flux inferred from atmospheric $\mathrm{CO}_{2}$ observations and its regional analyses," Biogeosciences, vol. 8, no. 11, pp. 3263-3281, 2011.

[39] K. Schuldt, J. Mund, I. T. Luijkx et al., Multi-laboratory compilation of atmospheric carbon dioxide data for the period 19572019, obspack_co2_1_GLOBALVIEWplus_v6.0_2020-09-11, NOAA Earth System Research Laboratory, Global Monitoring The Laboratory, 2020.

[40] D. Wunch, P. O. Wennberg, G. C. Toon et al., "A method for evaluating bias in global measurements of $\mathrm{CO}_{2}$ total columns from space," Atmospheric Chemistry and Physics, vol. 11, no. 23, pp. 12317-12337, 2011.

[41] D. Wunch, G. C. Toon, V. Sherlock et al., The Total Carbon Column Observing Network's GGG2014 Data Version, Pasadena, California, 2015.

[42] D. Wunch, J. Mendonca, O. Colebatch et al., "TCCON data from East Trout Lake, Canada, Release GGG2014R0," in TCCON Data Archive, hosted by CaltechDATA, California Institute of Technology, Pasadena, CA, USA, 2017.

[43] T. Blumenstock, F. Hase, M. Schneider, O. E. García, and E. Sepúlveda, "TCCON data from Izana, Tenerife, Spain, Release GGG2014R1," in TCCON Data Archive, hosted by CaltechDATA, California Institute of Technology, Pasadena, CA, USA, 2017.

[44] M. De Maziere, M. K. Sha, F. Desmet et al., "TCCON data from Reunion Island (La Reunion), France, Release GGG2014R0," in TCCON Data Archive, hosted by CaltechDATA, California Institute of Technology, Pasadena, CA, USA, 2017.

[45] N. Deutscher, J. Notholt, J. Messerschmidt et al., "TCCON data from Bialystok, Poland, Release GGG2014R1," in TCCON Data Archive, hosted by CaltechDATA, California Institute of Technology, Pasadena, CA, USA, 2017.

[46] D. G. Feist, S. G. Arnold, N. John, and M. C. Geibel, "TCCON data from Ascension Island, Saint Helena, Ascension and Tristan da Cunha, Release GGG2014R0," in TCCON Data Archive, hosted by CaltechDATA, California Institute of Technology, Pasadena, CA, U.S.A, 2017.

[47] T. Y. Goo, Y. S. Oh, and V. A. Velazco, "TCCON data from Anmeyondo, South Korea, Release GGG2014R0," in TCCON Data Archive, hosted by CaltechDATA, California Institute of Technology, Pasadena, CA, U.S.A, 2017.

[48] D. W. T. Griffith, N. Deutscher, V. A. Velazco et al., "TCCON data from Darwin, Australia, Release GGG2014R0," in TCCON Data Archive, hosted by CaltechDATA, California Institute of Technology, Pasadena, CA, USA, 2017.

[49] D. W. T. Griffith, V. A. Velazco, N. Deutscher et al., "TCCON data from Wollongong, Australia, Release GGG2014R0," in TCCON Data Archive, hosted by CaltechDATA, California Institute of Technology, Pasadena, CA, USA, 2017. 
[50] F. Hase, T. Blumenstock, S. Dohe, J. Groß, and M. Kiel, "TCCON data from Karlsruhe, Germany, Release GGG2014R1," in TCCON Data Archive, hosted by CaltechDATA, California Institute of Technology, Pasadena, CA, USA, 2017.

[51] L. Iraci, J. Podolske, P. Hillyard et al., "TCCON data from Armstrong Flight Research Center, Edwards, CA, USA, Release GGG2014R1," in TCCON Data Archive, hosted by CaltechDATA, California Institute of Technology, Pasadena, CA, USA, 2017.

[52] R. Kivi, P. Heikkinen, and E. Kyro, "TCCON data from Sodankyla, Finland, Release GGG2014R0," in TCCON Data Archive, hosted by CaltechDATA, California Institute of Technology, Pasadena, CA, USA, 2017.

[53] I. Morino, T. Matsuzaki, and A. Shishime, "TCCON data from Tsukuba, Ibaraki, Japan, 125HR, Release GGG2014R2," in TCCON Data Archive, hosted by CaltechDATA, California Institute of Technology, Pasadena, CA, USA, 2017.

[54] I. Morino, N. Yokozeki, T. Matzuzaki, H. Ikegami, and A. Shishime, "TCCON data from Rikubetsu, Hokkaido, Japan, Release GGG2014R1," in TCCON Data Archive, hosted by CaltechDATA, California Institute of Technology, Pasadena, CA, USA, 2017.

[55] I. Morino, V. A. Velazco, A. Hori, O. Uchino, and D. W. T. Griffith, "TCCON Data from Burgos, Ilocos Norte (PH), Release GGG2014.R0," in TCCON Data Archive, hosted by CaltechDATA, California Institute of Technology, Pasadena, CA, USA, 2018.

[56] J. Notholt, C. Petri, T. Warneke et al., “TCCON data from Bremen, Germany, Release GGG2014R1," in TCCON Data Archive, hosted by CaltechDATA, California Institute of Technology, Pasadena, CA, USA, 2019.

[57] J. Notholt, O. Schrems, T. Warneke et al., "TCCON data from Ny Alesund, Spitzbergen, Norway, Release GGG2014R1," in TCCON Data Archive, hosted by CaltechDATA, California Institute of Technology, Pasadena, CA, USA, 2019.

[58] V. Sherlock, B. Connor, J. Robinson, H. Shiona, D. Smale, and D. Pollard, "TCCON data from Lauder, New Zealand, $125 \mathrm{HR}$, Release GGG2014R0," in TCCON Data Archive, hosted by CaltechDATA, California Institute of Technology, Pasadena, CA, USA, 2017.

[59] K. Shiomi, S. Kawakami, H. Ohyama et al., "TCCON data from Saga, Japan, Release GGG2014R0," in TCCON Data Archive, hosted by CaltechDATA, California Institute of Technology, Pasadena, CA, USA, 2017.

[60] K. Strong, J. Mendonca, D. Weaver et al., "TCCON data from Eureka, Canada, Release GGG2014R2," in TCCON Data Archive, hosted by CaltechDATA, California Institute of Technology, Pasadena, CA, USA, 2017.

[61] R. Sussmann and M. Rettinger, "TCCON data from Garmisch, Germany, Release GGG2014R2," in TCCON Data Archive, hosted by CaltechDATA, California Institute of Technology, Pasadena, CA, USA, 2018.

[62] Y. Te, P. Jeseck, and C. Janssen, "TCCON data from Paris, France, Release GGG2014R0," in TCCON Data Archive, hosted by CaltechDATA, California Institute of Technology, Pasadena, CA, USA, 2017.

[63] T. Warneke, J. Messerschmidt, J. Notholt et al., "TCCON data from Orleans, France, Release GGG2014R0," in TCCON Data Archive, hosted by CaltechDATA, California Institute of Technology, Pasadena, CA, USA, 2017.
[64] P. O. Wennberg, C. Roehl, D. Wunch et al., "TCCON data from Park Falls, Wisconsin, USA, Release GGG2014R1," in TCCON Data Archive, hosted by CaltechDATA, California Institute of Technology, Pasadena, CA, USA, 2017.

[65] P. O. Wennberg, D. Wunch, C. Roehl et al., "TCCON data from Lamont, Oklahoma, USA, Release GGG2014R1," in TCCON Data Archive, hosted by CaltechDATA, California Institute of Technology, Pasadena, CA, USA, 2017.

[66] P. O. Wennberg, C. Roehl, J. F. Blavier, D. Wunch, J. Landeros, and N. Allen, "TCCON data from Jet Propulsion Laboratory, Pasadena, California, USA, Release GGG2014R1," in TCCON Data Archive, hosted by CaltechDATA, California Institute of Technology, Pasadena, CA, USA, 2017.

[67] P. O. Wennberg, C. Roehl, J. F. Blavier, G. C. Toon, and N. T. Allen, "TCCON data from California Institute of Technology, Pasadena, California, USA, Release GGG2014R1," in TCCON Data Archive, hosted by CaltechDATA, California Institute of Technology, Pasadena, CA, USA, 2017.

[68] T. J. Conway, P. P. Tans, L. S. Waterman et al., "Evidence for interannual variability of the carbon cycle from the National Oceanic and Atmospheric Administration/Climate Monitoring and Diagnostics Laboratory Global Air Sampling Network," Journal of Geophysical Research, vol. 99, no. D11, pp. 22831-22855, 1994.

[69] F. Deng, D. B. A. Jones, D. K. Henze et al., "Inferring regional sources and sinks of atmospheric $\mathrm{CO}_{2}$ from GOSAT $\mathrm{XCO}_{2}$ data," Atmospheric Chemistry and Physics, vol. 14, no. 7, pp. 3703-3727, 2014.

[70] F. Jiang, H. Wang, J. M. Chen et al., "Regional $\mathrm{CO}_{2}$ fluxes from 2010 to 2015 inferred from GOSAT $\mathrm{XCO}_{2}$ retrievals using a new version of the Global Carbon Assimilation System," Atmospheric Chemistry and Physics, vol. 21, no. 3, pp. 19631985, 2021.

[71] D. J. Hayes, R. Vargas, S. R. Alin et al., "Chapter 2: the North American carbon budget," Second State of the Carbon Cycle Report (SOCCR2): a sustained assessment report, U.S. Global Change Research Program, Washington, DC, USA, 2018.

[72] R. L. Thompson, P. K. Patra, F. Chevallier et al., "Top-down assessment of the Asian carbon budget since the mid 1990s," Nature Communications, vol. 7, no. 1, article 10724, 2016.

[73] G. Monteil, G. Broquet, M. Scholze et al., "The regional European atmospheric transport inversion comparison, EUROCOM: first results on European-wide terrestrial carbon fluxes for the period 2006-2015," Atmospheric Chemistry and Physics, vol. 20, no. 20, pp. 12063-12091, 2020.

[74] F. Jiang, J. M. Chen, L. X. Zhou et al., "A comprehensive estimate of recent carbon sinks in China using both top-down and bottom-up approaches," Scientific Reports, vol. 6, no. 1, 2016.

[75] J. Wang, L. Feng, P. I. Palmer et al., "Large Chinese land carbon sink estimated from atmospheric carbon dioxide data," Nature, vol. 586, no. 7831, pp. 720-723, 2020.

[76] D. J. Hayes, A. D. McGuire, D. W. Kicklighter, K. R. Gurney, T. J. Burnside, and J. M. Melillo, "Is the northern highlatitude land-based CO2sink weakening?," Global Biogeochemical Cycles, vol. 25, no. 3, article GB3018, 2011.

[77] S. Nilsson, E. A. Vaganov, A. Shvidenko et al., "Carbon budget of vegetation ecosystems of Russia," Doklady Biological Sciences, vol. 363A, pp. 1281-1283, 2003.

[78] A. J. Dolman, A. Shvidenko, D. Schepaschenko et al., "An estimate of the terrestrial carbon budget of Russia using 
inventory-based, eddy covariance and inversion methods," Biogeosciences, vol. 9, no. 12, pp. 5323-5340, 2012.

[79] D. G. Zamolodchikov, V. I. Grabovskii, P. P. Shulyak, and O. V. Chestnykh, "Recent decrease in carbon sink to Russian forests," Doklady Biological Sciences, vol. 476, no. 1, pp. 200202, 2017.

[80] P. Ciais, A. Bombelli, M. Williams et al., "The carbon balance of Africa: synthesis of recent research studies," Philosophical transactions of the royal society A: Mathematical, Physical and Engineering Sciences, vol. 369, pp. 2038-2057, 2011.

[81] J. Wang, N. Zeng, M. Wang et al., "Interannual variability of the atmospheric $\mathrm{CO}_{2}$ growth rate: roles of precipitation and temperature," Biogeosciences, vol. 13, no. 8, pp. 2339-2352, 2016.

[82] J. Wang, N. Zeng, M. Wang et al., "Interannual variability of the atmospheric $\mathrm{CO}_{2}$ growth rate: roles of precipitation and temperature," Atmospheric Chemistry and Physics, vol. 18, no. 14, pp. 10333-10345, 2018.

[83] J. Wang, M. Wang, J. S. Kim et al., "Modulation of land photosynthesis by the Indian Ocean dipole: satellite-based observations and CMIP6 future projections," Earths Future, vol. 9, no. $4,2021$.

[84] J. Liu, L. Baskaran, K. Bowman et al., "Carbon Monitoring System Flux Net Biosphere Exchange 2020 (CMS-Flux NBE 2020)," Earth System Science Data, vol. 13, no. 2, pp. 299330, 2021.

[85] P. I. Palmer, L. Feng, D. Baker, F. Chevallier, H. Bösch, and P. Somkuti, "Net carbon emissions from African biosphere dominate pan-tropical atmospheric $\mathrm{CO}_{2}$ signal," Nature Communications, vol. 10, no. 1, p. 3344, 2019.

[86] C. W. O'Dell, A. Eldering, P. O. Wennberg et al., "Improved retrievals of carbon dioxide from Orbiting Carbon Observatory-2 with the version 8 ACOS algorithm," Atmospheric Measurement Techniques, vol. 11, no. 12, pp. 65396576, 2018. 